\title{
The Most Dominant Predictability Factor of Boey Score on the Level of Mortality in Perforation Gaster Boey Score 1 and Boey Scores 2 Patients in RSUD Dr Soetomo
}

\section{Surabaya}

\section{Sandi Halim Naga Saputra ${ }^{*}$, Vicky Sumarki Budipramana², Marjono Dwi Wibowo²}

${ }^{1}$ General Surgery Resident, Faculty of Medicine, Airlangga University / RSUD Dr. Soetomo Surabaya

${ }^{2}$ SMF / Lab Teaching Staff. Surgery Faculty of Medicine, Airlangga University / Dr. Soetomo Surabaya

A R T I C L E I N F O

Keywords:

perforation gaster

Boey score

mortality

*Corresponding author:

Sandi Halim Naga Saputra

E-mail address:

sandihalim25@gmail.com

All authors have reviewed and approved the final version of the manuscript.

https://doi.org/10.32539/bsm.v5i10.357

\section{A B S T R A C T}

Background: The Boey score is the most commonly used scoring system for risk stratification because of its simplicity and high predictive value for mortality and morbidity in cases of gastric perforation. This score is widely used in daily practice because it only assesses 3 assessment components; namely the onset of perforation, shock at first admission, and comorbid disease; which is easy to do and has a fairly good accuracy. In Boey score 2, the mortality rate is still high, so research on the factors that most influence mortality at Boey Score 2 needs to be done. Methods: This study uses secondary data from medical records of patients who meet criteria of inclusion and exclusion. This study is a comparative test using a cohort analytic observational study design (longitudinal retrospective), comparing the components of the Boey score which is the most influential in predicting the mortality rate in gastric perforated patients. Boey score 1 and Boey score 2 at RSUD Dr. Soetomo Surabaya Results: Total subject of the study was 65 people, consisting of 43 men $(66.2 \%)$ and 22 women $(33.8 \%)$. The Boey score was 16 people $(24.6 \%)$ with a Boey score of 1 and 49 people $(75.4 \%)$ with a Boey score 2 .From the Boey score component, 49 people $(75.4 \%)$ were obtained with the onset of perforation $>24$ hours, 31 people $(47.7 \%)$ with preoperative shock, and 34 people $(52.3 \%)$ with comorbidities . Comorbidity in study subjects included hypertension in 17 people $(26.2 \%)$, diabetes mellitus in 4 people $(6.2 \%)$, heart disease in 4 people $(6.2 \%)$, lung disease in 5 people $(7.7 \%)$, and kidney disease in 7 people. people $(10.8 \%)$ Conclusion: Shock is the most dominant Boey Score predictability factor that affects the mortality rate in gastric perforation patients with Boey score 1 and Boey score 2 .

\section{Introduction}

The Boey score is the most common used scoring system for risk stratification because of its simplicity and high predictive value for mortality and morbidity in cases of gastric perforation. This score is widely used because it is easy in daily practice because it only assesses 3 variables components; namely the onset of perforation, shock at first admission, and comorbid disease; which is easy to do and has pretty good accuracy. $1,8,9$

A preliminary study by Boey et al showed that patients with risk factors $0,1,2$ and 3 who underwent laparotomy had a mortality rate of $0 \%, 14.1 \%, 58 \%$ and 100\%.2 The results of Boey's research (1982) are almost the same as the results of research conducted at the Dr. Soetomo Hospital in Surabaya, it was found that from a total of 33 cases of gastric perforation performed by laparotomy in 2018, 27.3\% of cases of gastric perforation were obtained with a Boey score 2 assessment with a mortality rate of 11.1 . \%. In 2019 from January to June. From a total of 27 cases, 37\% of cases were gastric perforation with a Boey score 2 assessment with a mortality rate of $50 \% .3,4,5,6,7$

The results of these study indicates that in the Boey score 2 , the mortality rate is still high, so research on the factors that most influence mortality at Boey Score 2 needs to be done, because from the existing research on the Boey score there is an inconsistency of the factors that most determine mortality between one 
research to another.

\section{Methods}

The study design is a comparative test using a cohort analytic observational study design (longitudinal retrospective), comparing the components of the Boey score which one is the most influential in predicting the mortality rate in gastric perforated patients with Boey score 1 and Boey score 2 at RSUD Dr. Soetomo Surabaya. The cohort study was carried out during the patient care in the hospital.

The inclusion criteria of this study were the medical records of patients with gastric perforation Boey Score 1 in RSUD Dr. Soetomo, medical records of patients with gastric perforation Boey Score 2 at Dr. Soetomo,
Patient with gastric perforation Boey Score 1 at RSUD Dr. Soetomo, who underwent a gastric repair surgery using the Cellan Jones Patch technique, a patient with gastric perforation Boey Score 2 at Dr. Soetomo performed gastric repair surgery using the Cellan Jones Patch Technique. Exclusion criteria were patients who died during treatment due to other causes (pneumonia, heart attack), incomplete medical records.

\section{Results}

In this study, a total subject of the study was 65 people, consisting of 43 men $(66.2 \%)$ and 22 women $(33.8 \%)$. From the patient age group, it was found that the highest age was in the 51-60 years age group with 26 people (40\%) and the least in the 21-30 year age group, namely 2 people (3.1\%).

Table 1. Characteristic of Subject Research

\begin{tabular}{llcc}
\hline \multicolumn{2}{c}{ Characteristic } & $\mathbf{n}$ & Percentage \\
\hline Sex & Men & 43 & $66.2 \%$ \\
\cline { 2 - 4 } & Women & 22 & $33.8 \%$ \\
\hline Age & $21-30$ y.o & 2 & $3.1 \%$ \\
\cline { 2 - 4 } & $31-40$ y.o & 4 & $6.2 \%$ \\
\cline { 2 - 4 } & $41-50$ y.o & 20 & $30.8 \%$ \\
\cline { 2 - 4 } & $51-60$ y.o & $26 \%$ & $20 \%$ \\
\hline
\end{tabular}

According to the Boey score result, 16 people $(24.6 \%)$ were obtained with a Boey score of 1 and 49 people $(75.4 \%)$ with a Boey score 2 . From the Boey score component, 49 people $(75.4 \%)$ were obtained with the onset of perforation> 24 hours, 31 people $(47.7 \%)$ with preoperative shock, and 34 people (52.3\%) with comorbidities. Comorbidity in study subjects included hypertension in 17 people (26.2\%), diabetes mellitus in 4 people $(6.2 \%)$, heart disease in 4 people $(6.2 \%)$, lung disease in 5 people $(7.7 \%)$, and kidney disease in 7 people. people $(10.8 \%)$.

Table 2. Relationship Between Boey Score and Mortality

\begin{tabular}{|c|c|c|c|c|}
\hline & & \multicolumn{2}{|c|}{ Mortality } & \multirow[t]{2}{*}{ P Value } \\
\hline & & Yes & No & \\
\hline \multirow[t]{2}{*}{ Boey Score } & Boey 2 & $31(63.3 \%)$ & $18(36.7 \%)$ & \\
\hline & Boey 1 & $4(25 \%)$ & $12(75 \%)$ & 0.008 \\
\hline Total & & 35 (53.8\%) & $30(46.2)$ & \\
\hline
\end{tabular}


The mortality rate was found as many as 22 people $(70.9 \%)$ in the group with shock and as many as 13 people $(38.2 \%)$ in the group without shock. Chi-square statistical test showed significant differences in the two groups with $\mathrm{p}=0.008(\mathrm{p}<0.05)$.

Table 3. Correlation Between Shock and Mortality

\begin{tabular}{|c|c|c|c|c|}
\hline & & \multicolumn{2}{|c|}{ Mortality } & \multirow[t]{2}{*}{ P Value } \\
\hline & & Yes & No & \\
\hline \multirow[t]{2}{*}{ Preoperative Shock } & Yes & $22(70.9 \%)$ & 9 (29.1\%) & \\
\hline & No & $13(38.2 \%)$ & $21(61.8 \%)$ & 0.008 \\
\hline Total & & 35 (53.8\%) & $30(46.2)$ & \\
\hline
\end{tabular}

The mortality rate was found as many as 17 people (50\%) in the comorbid group and as many as 18 people $(58 \%)$ in the non-comorbid group. Statistical test using
Chi-square found no significant difference in the two groups with $\mathrm{p}=0.515(\mathrm{p}>0.05)$.

Table 4. Correlation Between Comorbid Illnes and Mortality

\begin{tabular}{|c|c|c|c|c|}
\hline & & \multicolumn{2}{|c|}{ Mortality } & \multirow[t]{2}{*}{ P Value } \\
\hline & & Yes & No & \\
\hline \multirow[t]{2}{*}{ Comorbidity } & Yes & 17 (50\%) & 17 (50\%) & \\
\hline & No & $18(58 \%)$ & 13 (42\%) & 0.515 \\
\hline Total & & 35 (53.8\%) & $30(46.2)$ & \\
\hline
\end{tabular}

\section{Discussion}

The Boey score scoring system is one of the predictive systems for prognosis in patients with gastric perforation. This system helps in the prediction of patient outcome because often patients with gastric perforations have high morbidity and mortality rates.5 The analysis of the total Boey score showed a significant result in accordance with previous research studies which showed that increasing the Boey score would increase the risk of mortality in patients. 1,11,12

From the results of the regression analysis, it was found that the Boey score component found the most dominant factor is preoperative shock. Binary logistic regression analysis showed that preoperative shock had a greater role in predicting mortality $(\mathrm{p}=0.001$, with exponent (B) 7,911), whereas onset and less comorbidity were seen to have a greater effect on mortality in gastric perforated patients in this study.
Preoperative shock in patients with gastric perforation arises mainly due to 2 main reasons dehydration due to decreased fluid intake and the result of sepsis arising from peritonitis in the patient. These two conditions aggravate each other where both will further reduce the hemodynamic condition in the patient and increase injury to other organs. Mortality due to sepsis is still high worldwide, with a rate ranging from $25-80 \%$ of patients with sepsis. 12

The onset of perforation in this study was also influential in predicting patient mortality. The onset of perforation until the time medical action is given indicates the duration of peritoneal contamination. The longer the duration of the contamination will increase the degree of inflammation that occurs which results in an increase in the severity of the peritonitis that occurs. The longer the duration of peritonitis also affects the occurrence of sepsis in the patient.13 Meanwhile, comorbidities in patients from this study did not show 
any significance in predicting mortality. This can be due to the comorbidity is not directly related to the patient's sepsis condition, so it does not have much effect.

Shock in gastric perforation is commonly due to a septic shock that occurs when infectious microorganisms in the bloodstream causing an inflammatory response that causes hemodynamic decompensation. Pathogenesis involves a complex response of cellular activation that triggers the release of many proinflammatory mediators. This inflammatory response causes activation of leucocytes and endothelial cells, as well as activation of the coagulation system. The excessive inflammatory response that characterizes septic shock is primarily driven by tumor necrosis factor cytokines alpha (TNFa) and interleukin-1 (IL-1), which are produced by mono-sites in response to infection. This shock condition plays a role in the decrease in tissue perfusion which results in organ system failure and ends in death. $14,15,16,17$

\section{Conclusion}

Shock is the most dominant Boey Score predictability factor that affects the mortality rate in gastric perforation patients with Boey score 1 and Boey score 2.

\section{References}

1. Dhruba, S. (2019) 'Boey Score in Predicting Outcome in Perforated Peptic Ulcer from Tertiary Referral Center of Nepal', ARC Journal of Surgery, 5(1), pp. 9-14. doi: 10.20431/2455-572x.0501002

2. Boey, J. and Wong, J. (1982) 'A prospective study of operative risk factors in perforated duodenal ulcers', Annals of Surgery, 195(3), pp. 265-269. doi: 10.1097/00000658198203000-00004.

3. Lestari, W. B. (2017) 'Sistem Skor Prognostik Morbiditas Pasca-Operasi Untuk Pasien Perforasi Ulkus Peptik Gaster'.

4. Kim, J. M. et al. (2012) 'Analysis of risk factors for postoperative morbidity in perforated peptic ulcer', Journal of Gastric Cancer, 12(1), pp. 26-35. doi: 10.5230/jgc.2012.12.1.26

5. Agarwal, A. et al. (2015) 'Validation of Boey's score in predicting morbidity and mortality in peptic perforation peritonitis in Northwestern India', Tropical gastroenterology: official journal of the Digestive Diseases Foundation, 36(4), pp. 256-260. doi: 10.7869/tg.300.

6. Chung, K. T. and Shelat, V. G. (2017) 'Perforated peptic ulcer - an update', World Journal of Gastrointestinal Surgery, 9(1), p. 1. doi: 10.4240/wjgs.v9.i1.1.

7. Bucher, P. et al. (2007) 'Results of conservative treatment for perforated gastroduodenal ulcer in patients not eligible for surgical repair', Swiss Medical Weekly, 137(23-24), pp. 337340. doi: 2007/23/smw-11796.

8. Budipramana, V. S. (2019) 'LACTATE LEVEL AS A PREDICTION FACTOR OF REPERFORATION AFTER REPAIRING GASTRIC PERFORATION', 55(1), pp. 43-47.

9. Anbalakan, K. et al. (2015) 'Five year experience in management of perforated peptic ulcer and validation of common mortality risk prediction models - Are existing models sufficient? A retrospective cohort study', International Journal of Surgery. Elsevier Ltd, 14, pp. 38-44. doi: 10.1016/j.ijsu.2014.12.022.

10. Thorsen, K., Søreide, J. A. and Søreide, K. (2013) 'Scoring systems for outcome prediction in patients with perforated peptic ulcer', Scandinavian journal of trauma, resuscitation and emergency medicine. BioMed Central, 21, p. 25. doi: 10.1186/1757-7241-21-25.

11. Thorsen, K., Søreide, J. A. and Søreide, K. (2014) What Is the Best Predictor of Mortality in Perforated Peptic Ulcer Disease? A Population-Based, Multivariable Regression Analysis Including Three Clinical Scoring Systems', Journal of Gastrointestinal Surgery, 18(7), pp. 1261-1268. doi: 10.1007/s11605014-2485-5.

12. Armen, S. B. et al. (2016) 'Improving Outcomes 
in Patients With Sepsis', American journal of medical quality: the official journal of the American College of Medical Quality. 2014/09/12, 31(1), pp. 56-63. doi: $10.1177 / 1062860614551042$.

13. Thirumalagiri, V. R., Reddy J., S. R. and T., H. C. (2017) 'Acute peritonitis secondary to hollow viscous perforation: a clinical study', International Surgery Journal, 4(7), p. 2262. doi: 10.18203/2349-2902.isj20172778.

14. Trzeciak, S., Dellinger, R. P. and Parrillo, J. E. (2008) 'Septic Shock', in Critical Care Medicine. Elsevier, pp. 439-452. Available at: https:/ / linkinghub.elsevier.com/retrieve/pii/ B9780323048415500261.

15. Surapaneni, S., Rajkumar, S. and Vijaya Bhaskar Reddy, A. (2013) The perforationoperation time interval; an important mortality indicator in peptic ulcer perforation', Journal of Clinical and Diagnostic Research, 7(5), pp. 880-882. doi: 10.7860/JCDR/2013/4925.2965.

16. Tarasconi, A. et al. (2020) 'Perforated and bleeding peptic ulcer: WSES guidelines', World Journal of Emergency Surgery. World Journal of Emergency Surgery, 15(1), pp. 1-24. doi: 10.1186/s13017-019-0283-9.

17. Gona, S. K. et al. (2016) 'Postoperative Morbidity and Mortality of Perforated Peptic Ulcer: Retrospective Cohort Study of Risk Factors among Black Africans in Côte d'Ivoire', Gastroenterology Research and Practice. Hindawi Publishing Corporation, 2016. doi: 10.1155/2016/2640730. 